\title{
Comparison of Dural Splitting and Duraplasty in Patients with Chiari Type I Malformation: Relationship between Tonsillo-Dural Distance and Syrinx Cavity
}

\author{
Sukru ORAL ${ }^{1}$, Atilla YILMAZ¹, Ahmet KUCUK², Abdulfettah TUMTURK², Ahmet MENKU³ \\ ${ }^{1}$ Mustafa Kemal University, School of Medicine, Department of Neurosurgery, Hatay, Turkey \\ ${ }^{2}$ Erciyes University, School of Medicine, Department of Neurosurgery, Kayseri, Turkey \\ ${ }^{3}$ Memorial Hospital, Department of Neurosurgery, Kayseri, Turkey \\ Corresponding author: Sukru ORAL sukruor@yahoo.com \\ To watch the surgical videoclip, please visit http://turkishneurosurgery.org.tr/images/23319-video.mp4
}

\section{ABSTRACT}

AIM: To compare the clinical and radiological results of dural splitting and duraplasty in patients with Chiari Type I Malformation.

MATERIAL and METHODS: This study includes 113 adult patients with Chiari Type I malformation treated between 2009 and 2013. The patients were divided into two groups according to the surgical method (Group 1: dural splitting, Group 2: duraplasty). Neurological examinations and magnetic resonance imaging (MRI) scans were recorded periodically on 3rd, 6th,and 12th months at the postoperative period. The tonsillo-dural distance (TDD) and regression rate of the syrinx cavity were measured on T1 and T2 weighted sagittal MRI scans at the postoperative period.

RESULTS: The ratio of syrinx regression was $\% 49.6$ in the Group 1 and $\% 54.6$ in the Group 2 . This result was statistically significant. The TDD increased in Group 2 and this result was statistically significant $(p<0.05)$. Postoperative pain and numbness decreased in both groups and no statistically significant difference was detected.

CONCLUSION: There was no relationship between tonsillar herniation length and the width of syringomyelic cavity. The syrinx cavity more regressed in the group 2 than group 1. There was no relation between the TDD and the ratio of syrinx regression.

KEYWORDS: Chiari type I malformation, Duraplasty, Dural splitting

\section{INTRODUCTION}

$\mathrm{T}$ Type I Chiari malformation (CMI) is characterized by cerebellar tonsil herniation through the foramen magnum into the cervical spinal canal $(2,3)$. Although $30 \%$ of patients are asymptomatic, progressive and severe neurological deficits are also observed $(13,14)$. Clinical findings usually appear in the third and fourth decades of life. Magnetic resonance imaging (MRI) is the gold standard test for diagnosing CMI. Computed tomography and X-ray images are important for evaluating accompanying anomalies of vertebrae and cranial bones. Today, posterior fossa decompression is the most common surgical treatment method for CMI. In this study, we conducted clinical and radiological comparisons in 78 patients with $\mathrm{CMl}$ undergoing dural splitting and 35 patients with $\mathrm{CMI}$ undergoing duraplasty. Clinical evaluation and physical examination were performed at specific periods in the patients. In addition, as per our knowledge, this is the first study discussing the relationship between tonsillo-dural distance (TDD) and the syrinx cavity. Furthermore, the utility of intraoperative ultrasonography (USG) in cases requiring dural splitting was demonstrated.
SUkru ORAL (10): 0000-0003-4328-0690 Atilla YILMAZ (10) : 0000-0002-1081-3545
Ahmet KUCUK

(1) : 0000-0002-9198-9605 Abdulfettah TUMTURK (D) : 0000-0001-5883-9819
Ahmet MENKU (10): 0000-0003-4892-2939 


\section{MATERIAL and METHODS}

This study included 113 patients who underwent surgery for $\mathrm{CMI}$ at Erciyes University Medical Faculty Department of Neurosurgery. All patients were symptomatic and aged $>17$ years. This study was conducted with the approval of the Erciyes University Medical Faculty Ethics Committee $2012 / 712$. The patients were divided into two groups based on the surgical method: group 1(dural splitting) and group 2 (duraplasty). MRI was performed using a 1.5 Tesla system (Philips Intera MR System Release 12.6.1.4.2012). The images were transferred to a radiologic imaging system and measurements were performed (Infinitt Pacs 2002-2014 INFINITT Healthcare Co., Ltd.). In both groups, TDDs were measured on T2 mid-sagittal MR images after surgery and the results were compared (Figure $1 \mathrm{~A}$ ). In group 1, cerebrospinal fluid (CSF) flow was observed on intraoperative USG (Video 1). Syrinx ratios were measured on $T 1$ mid-sagittal $M R$ images before and after surgery (Figure 1B). In addition, the association between TDD and syrinx ratio was statistically evaluated. Neurological examinations of the patients were periodically recorded at 3,6 , and 12 months according to the scoring system defined by Klekamp et al. (8).

\section{Surgical Technique}

All patients were operated in the Concorde position under general anesthesia. For surgical prophylaxis, $1 \mathrm{~g}$ of cefazoline was intravenously administered 30 minutes prior to the operation. A midline incision was made extending from the occipital protuberance to the $\mathrm{C} 4$ spinous process. Decompressive suboccipital craniectomy and C1 laminectomy were performed in all patients using a high-speed drill. In group 2, a Y-shaped dural opening was performed and arachnoid bands between the tonsils were microsurgically released. After hemostasis, the galea aponeurotica was used for the duraplasty and tacked into place. In group 1, the fibrous bands on the outside of the dura were removed at the level of the foramen magnum. Horizontal and vertical incisions were made to the outer layer of the dura laterally from the midline. Further, ultrasonography was used to demonstrate CSF flow after dural splitting (Video 1).

\section{Statistical Analysis}

Data analysis was conducted using IBM SPSS Statistics software, version 22. We assessed for normality using two tests: Kolmogorov-Smirnov test and Shapiro-Wilk test. Unpaired $t$ test, Mann-Whitney $U$ test, and Wilcoxon signed-rank test were used for intergroup comparison of the parameters. Moreover, Pearson correlation coefficient was performed for correlation analysis, and $\mathrm{p}<0.05$ was considered significant.

\section{RESULTS}

Group 1 comprised 22 males and 56 females aged 19-66 years; group 2 comprised 21 males and 14 females aged 22-56 years. Males had a mean age of 37.8 years, and females had a mean age of 39.5 years. There was no statistical difference between the groups in terms of age ( $p>0.05)$. The patient demographic characteristics are presented in Table I. The most frequent complaints in both groups were suboccipital pain in $92 \%$ patients, then numbness in $60 \%$ patients. In addition, patients had nonspecific complaints, such as ataxia, dysphagia, vertigo, loss of balance, tremor, and seizure (Table I). The most common findings on neurological examination were sensory deficit in $21 \%$ patients, positive Romberg sign in $26 \%$, motor paresis in the extremities, and positive Hoffmann reflexes. The most common anomalies in these patients were scoliosis in $14 \%$ patients and syringomyelia [group 1 ( $n=40), 51 \%$; group 2 ( $n=17), 49 \%$; Table I]. Table I also shows rare pathologies, such as occipitalization of the atlas, block vertebra, platybasia, basilar invagination, Klippel-Feil syndrome, hydrocephalus, and intracranial arachnoid cyst. Mean herniated tonsillar length (HTL) was $12.35 \pm 4.75 \mathrm{~mm}$ in group 1 and $11.75 \pm 4.10 \mathrm{~mm}$ in group 2 (Table II). There was no significant difference in the HTL and no significant correlation
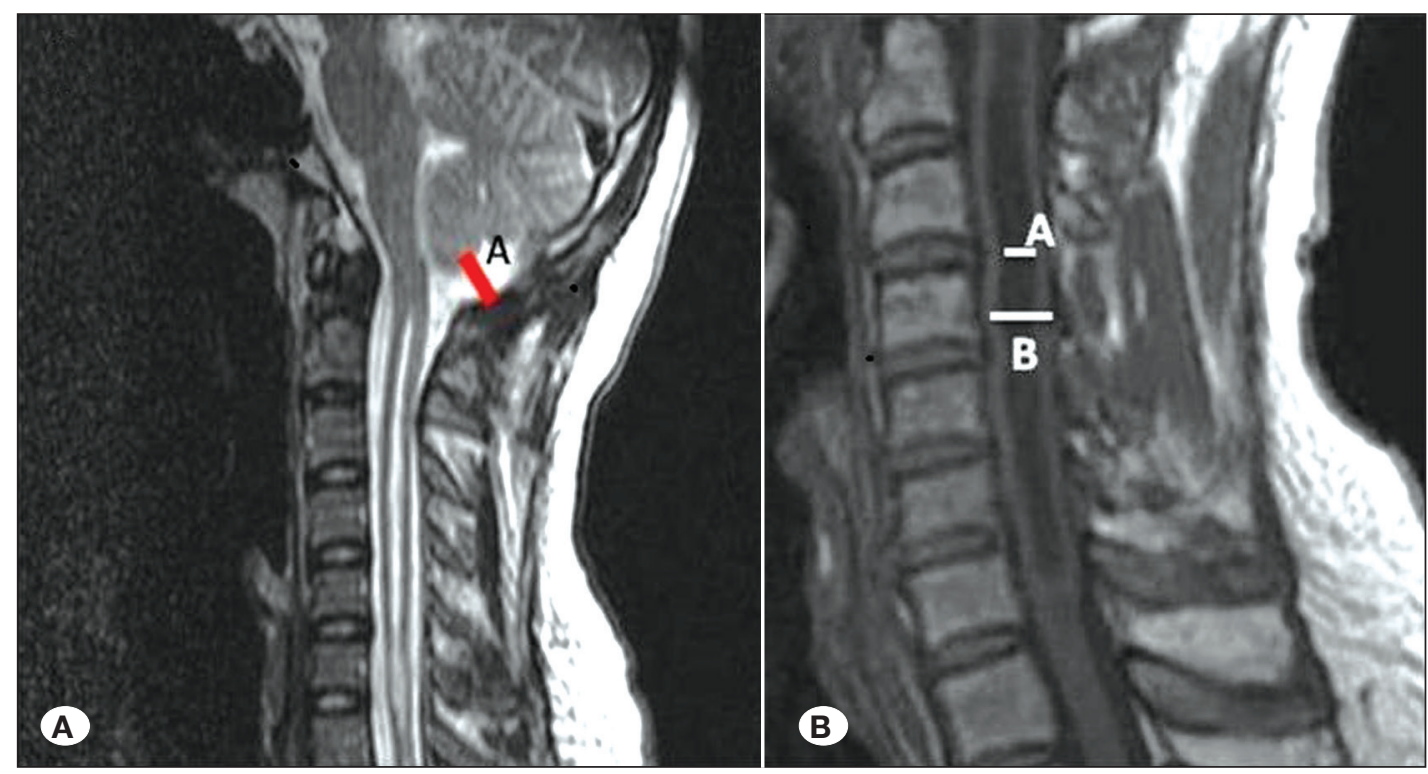

Figure 1: The

measurement technique for tonsillo-dural distance (A). The measurement technique for syrinx cavity ratio from the largest part $(\mathrm{Ax} 100 / \mathrm{B})$ (B) 
Table I: Demographic Information, Symptoms, Anomalies and Clinical Findings

\begin{tabular}{|c|c|c|}
\hline & $\begin{array}{c}\text { Group } 1 \\
(n=78)\end{array}$ & $\begin{array}{c}\text { Group } 2 \\
(n=35)\end{array}$ \\
\hline \multicolumn{3}{|l|}{ Sex } \\
\hline Male & 22 & 21 \\
\hline Female & 56 & 14 \\
\hline \multicolumn{3}{|l|}{ Symptomps } \\
\hline Suboccipital pain & $72(92 \%)$ & $31(89 \%)$ \\
\hline Numbness & $47(60 \%)$ & $19(54 \%)$ \\
\hline Imbalance & $14(18 \%)$ & $3(9 \%)$ \\
\hline Pain in extremities & $22(28 \%)$ & $14(40 \%)$ \\
\hline Ataxia & $11(14 \%)$ & $8(23 \%)$ \\
\hline Vertigo & $10(13 \%)$ & $4(11 \%)$ \\
\hline Diplopia & $2(3 \%)$ & 0 \\
\hline Tremor & $2(3 \%)$ & 0 \\
\hline Dyshagia & $2(3 \%)$ & $1(3 \%)$ \\
\hline Seizure & 0 & $2(6 \%)$ \\
\hline \multicolumn{3}{|l|}{ Clinical Findings } \\
\hline Sensory deficit & $16(21 \%)$ & $5(14 \%)$ \\
\hline Paresis & $9(12 \%)$ & $3(9 \%)$ \\
\hline Romberg Sign & $13(17 \%)$ & $9(25 \%)$ \\
\hline Pathological Reflex & $7(9 \%)$ & $3(9 \%)$ \\
\hline \multicolumn{3}{|l|}{ Accompanying Anomalies } \\
\hline Syrinx & $40(51 \%)$ & $17(49 \%)$ \\
\hline Scoliosis & $11(14 \%)$ & $5(14 \%)$ \\
\hline Hidrocephaly & $1(1 \%)$ & $1(3 \%)$ \\
\hline Klippel-Feil Syndrome & $1(1 \%)$ & 0 \\
\hline Arachnoid Cyst & 0 & $1(3 \%)$ \\
\hline Occipitalization of atlas & $3(3 \%)$ & 0 \\
\hline Block vertebrae & $1(1 \%)$ & 0 \\
\hline Platybasia & $2(2 \%)$ & 0 \\
\hline Basilar invagination & $1(1 \%)$ & 0 \\
\hline
\end{tabular}

between HTL and syringomyelia ( $p>0.05$, PK: -0.162$)$ between the groups. Postoperative TDD measured on T2 sagittal MRI was $5.52 \mathrm{~mm}$ in group 1 and $9.22 \mathrm{~mm}$ in group 2, and the increase in TDD in group 2 was statistically significant (Table II). The regression rate of the syrinx cavity (partial and total) at the postoperative sixth months was $49.6 \%$ in group 1 and $54.6 \%$ in group 2, and these results were statistically significant (Table II). However, there was no statistically significant difference between TDD and regression rate of the syrinx cavity in the sixth postoperative month between the groups. Neurological evaluations were performed regarding suboccipital pain, numbness, and ataxia preoperatively and postoperatively at 3,6 , and 12 months. Suboccipital pain decreased in both groups at 3 months, and the difference was statistically significant (Table III). Numbness decreased in both groups at 6 and 12 months, and the decrease observed at 12 months was statistically significant (Table III). There was no significant difference between the group 1 and group 2 (Table IV) and no significant difference in the ataxia test in the preoperative and postoperative periods between the two groups. Numbness did not improve in 7 patients in both groups (Table IV). The syrinx cavity regressed completely in 13 of 40 patients in group 1 and 5 of 17 in group 2 (Figure 2A-D, 3A-D). The syrinx remained unchanged in 7 of 40 patients in group 1 and 3 of 17 in group 2 who had a long multiseptated syrinx cavity extending throughout the entire spinal cord (Figure 4A). In group 1, 7 patients underwent reoperation with duraplasty and 3 underwent reduction of the syrinx cavity (Figure 4B). Dural splitting was performed in one patient and duraplasty in the other diagnosed with CMI. The hydrocephalus regressed within the 6-month follow-up period (Figure 5A-C).

\section{Complications}

Four patients in group 1 and 3 in group 2 had superficial wound infection. Two patients underwent surgical debridement, and antibiotherapy was administered to the remaining patients in group 1. Five patients in group 2 had postoperative CSF leak, of whom 3 underwent continuous CSF drainage. The remaining 2 patients underwent reoperation for dural repair. Bacterial meningitis developed in 2 patients; they were treated with appropriate antibiotics, followed closely, and had no sequelae.

Table II: Herniated Tonsillar Lengths in the Patients, Tonsillo-Dural Distance and the Regression Rates of Syrinx Cavity in the Groups (\%)

\begin{tabular}{|c|c|c|c|c|c|c|c|}
\hline & & $\mathbf{n}$ & Mean & $\begin{array}{l}\text { Standard } \\
\text { deviation }\end{array}$ & Minimum & Maximum & $\mathbf{p}$ \\
\hline \multirow{2}{*}{$\begin{array}{l}\text { Herniated tonsillar lengths in the } \\
\text { patients }\end{array}$} & Group 1 & 78 & $12.35 \mathrm{~mm}$ & 4.75 & 5.25 & 28.85 & $>0.05$ \\
\hline & Group 2 & 35 & $11.75 \mathrm{~mm}$ & 4.10 & 7.39 & 26.43 & $>0.05$ \\
\hline \multirow{2}{*}{ Tonsillo-Dural Distance } & Group 1 & 78 & $5.52 \mathrm{~mm}$ & 1.83 & 2.38 & 15.4 & 0.000 \\
\hline & Group 2 & 35 & $9.22 \mathrm{~mm}$ & 3.82 & 3.83 & 21.38 & 0.000 \\
\hline \multirow{2}{*}{$\begin{array}{l}\text { The regression rates of syrinx } \\
\text { cavity in the groups (\%) }\end{array}$} & Group 1 & 40 & 49.70 & 38.66 & & & 0.00 \\
\hline & Group 2 & 17 & 54.61 & 33.11 & & & 0.04 \\
\hline
\end{tabular}


Oral S. et al: Dural Splitting and Duraplasty in Chiari Malformation

Table III: Evaulation of Suboccipital Pain and Numbness Score in the Follow-up Period

\begin{tabular}{|c|c|c|c|c|c|c|c|c|}
\hline & & Preoperative & $\begin{array}{l}\text { Postoperative } \\
3^{\text {th }} \text { months }\end{array}$ & $\begin{array}{l}\text { Postoperative } \\
6^{\text {th }} \text { months }\end{array}$ & $\begin{array}{l}\text { Postoperative } \\
12^{\text {th }} \text { months }\end{array}$ & $\begin{array}{c}p \\
\left(\text { Pre-3 }^{\text {th }}\right)\end{array}$ & $\underset{\left(3^{\text {th }}-6^{\text {th }}\right)}{p}$ & $\underset{\left(6^{\text {th }}-12^{\text {th }}\right)}{p}$ \\
\hline \multirow{2}{*}{$\begin{array}{l}\text { Suboccipital } \\
\text { Pain Score }\end{array}$} & $\begin{array}{l}\text { Group } 1 \\
(n=72)\end{array}$ & 1.48 & 3.06 & 3.35 & 4.00 & 0.001 & 0.062 & 0.003 \\
\hline & $\begin{array}{l}\text { Group } 2 \\
(n=31)\end{array}$ & 1.90 & 3.25 & 3.68 & 4.13 & 0.002 & 0.063 & 0.003 \\
\hline \multirow{2}{*}{$\begin{array}{l}\text { Numbness } \\
\text { Score }\end{array}$} & $\begin{array}{l}\text { Group } 1 \\
(\mathrm{n}=72)\end{array}$ & 2.60 & 2.72 & 3.26 & 3.66 & 0.075 & 0.081 & 0.014 \\
\hline & $\begin{array}{l}\text { Group } 2 \\
(n=31)\end{array}$ & 2.63 & 2.89 & 3.16 & 3.74 & 0.069 & 0.072 & 0.003 \\
\hline
\end{tabular}

Table IV: Numbness and Suboccipital Pain Score in the Follow-up Period Between the Two Groups

\begin{tabular}{|c|c|c|c|c|}
\hline & & Group 1 ( $n=72)$ & Group 2 ( $n=31)$ & $P$ value \\
\hline \multirow{4}{*}{ Numbness Score } & Preoperative & 2.60 & 2.63 & 0.867 \\
\hline & Postoperative $3^{\text {th }}$ months & 2.72 & 2.89 & 0.136 \\
\hline & Postoperative $6^{\text {th }}$ months & 3.26 & 3.16 & 0.404 \\
\hline & Postoperative $12^{\text {th }}$ months & 3.66 & 3.74 & 0.626 \\
\hline \multirow{4}{*}{ Suboccipital Pain Score } & Preoperative & 1.48 & 1.90 & 0.07 \\
\hline & Postoperative $3^{\text {th }}$ months & 3.06 & 3.25 & 0.08 \\
\hline & Postoperative $6^{\text {th }}$ months & 3.35 & 3.68 & 0.06 \\
\hline & Postoperative $12^{\text {th }}$ months & 4.00 & 4.13 & 0.28 \\
\hline
\end{tabular}

\section{DISCUSSION}

Clinical findings are typically observed in patients with CMI with a mean of $25-45$ years. CMI symptoms may be seen earlier in patients with syringomyelia. Milhorat et al. reported that the mean age of $\mathrm{CM}$ patients was $35.9 \pm 16.8$ years, the female-to-male ratio was 3.08 , and the mean time to symptom onset was $25.2 \pm 14.2$ years (10). In the present study, the mean age of female patients was $39.5 \pm 12.5$ years, the mean age of male patients was $37.8 \pm 9.8$ years, and the female-tomale ratio was 1.6 , which is consistent with the findings of the literature.

Suboccipital pain decreased at 3 months postoperatively and was statistically significant in both groups. Similarly, the numbness score decreased significantly at 12 months postoperatively. However, most of the patients received gabapentin, vitamin $\mathrm{B}_{12}$, and pregabalin as treatment of postoperative neuropathic pain. In the Milhorat study, there was no significant change in ataxia. Aliaga et al. reported that of 146 patients with CMl who underwent duraplasty, 101 recovered, 39 showed no change, and 6 had deteriorated at the end of the first postoperative year (1). Vaidya and Sharma reported that numerous symptoms persisted in 13 patients following duraplasty, and they suggest that different surgical techniques should be applied according to the complications (15). Chauvet et al. reported dural splitting in 11 patients with
CMI. Symptoms completely improved in 6 patients, dizziness and paresthesia in the upper limb were unchanged in 3 patients, and no complications were observed (4).

$\mathrm{CMI}$ is characterized by a caudal descent of the cerebellar tonsil through the foramen magnum by no more than $3-5$ $\mathrm{mm}$. However, symptoms and signs of $\mathrm{CMI}$ and syringomyelia develop with less tonsil herniation $(12,13)$. In our study, the mean herniated tonsillar length was $12.16 \pm 4.5 \mathrm{~mm}$, and there was no significant relationship between HTL and the size of the syrinx cavity using Pearson correlation coefficient.

Erdogan et al. found more increased TDD in patients who had undergone duraplasty than dural splitting. In addition, they reported no difference in the surgical results in the dural split and duraplasty groups (5). In publications which related to the use of intraoperative USG were measured parameters such as CSF flow and CSF flow rate $(7,9,16)$. Isu et al. demonstrated that there was no CSF flow on intraoperative USG prior to dural splitting but that CSF flow was seen on USG after the outer layer of the dura was opened (7). Similarly, in the present study, CSF flow was not observed on intraoperative USG prior to the dural splitting in group 1. In addition, the syrinx cavity regressed more in group 1 than in group 2 at the end of the first postoperative year (54.61\%-49.6\%). Erdogan et al. reported that the syrinx regression rate was $28 \% \pm 10 \%$ in non-duraplasty group and $36 \% \pm 33 \%$ in duraplasty group. 

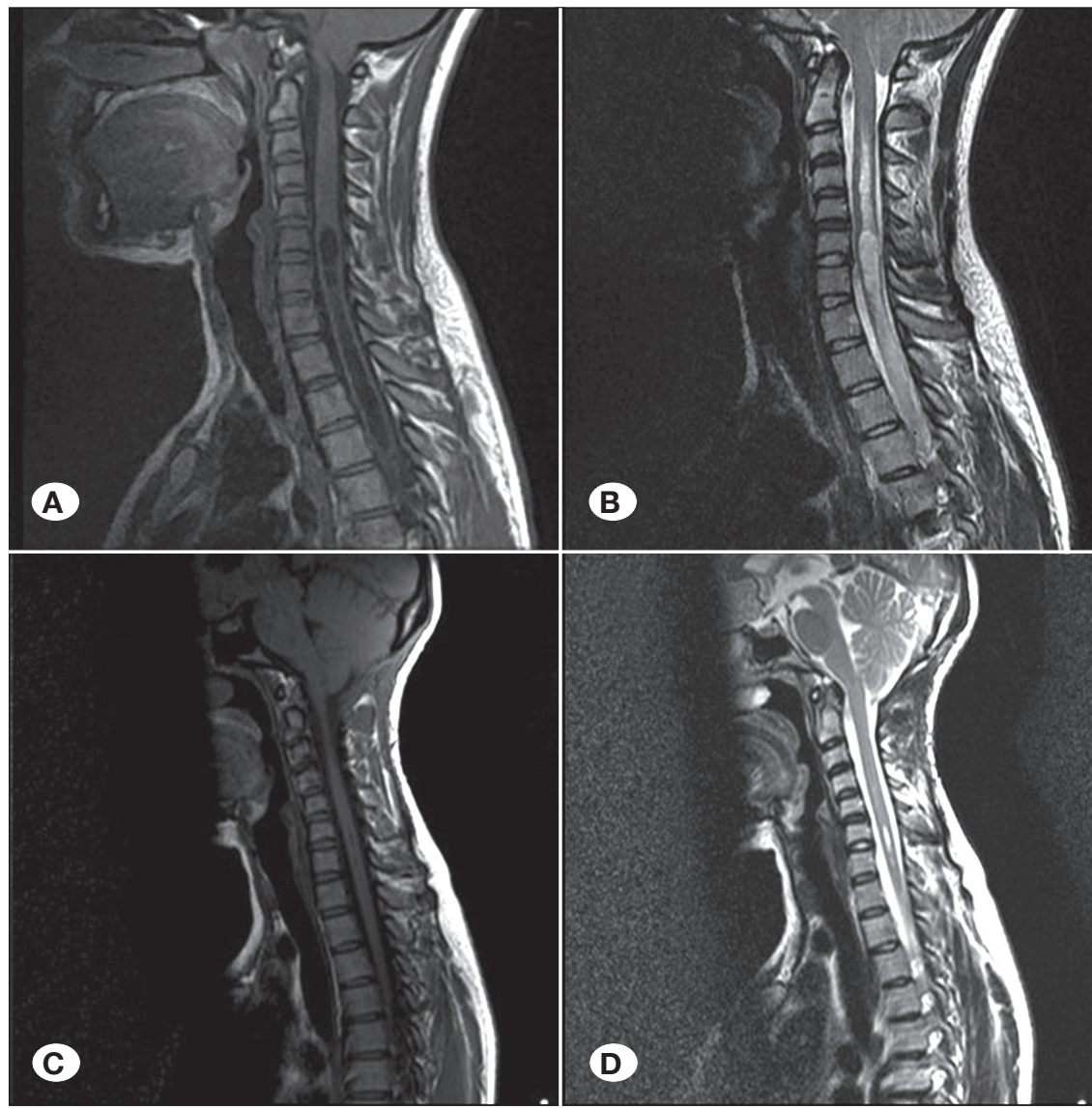

(D)
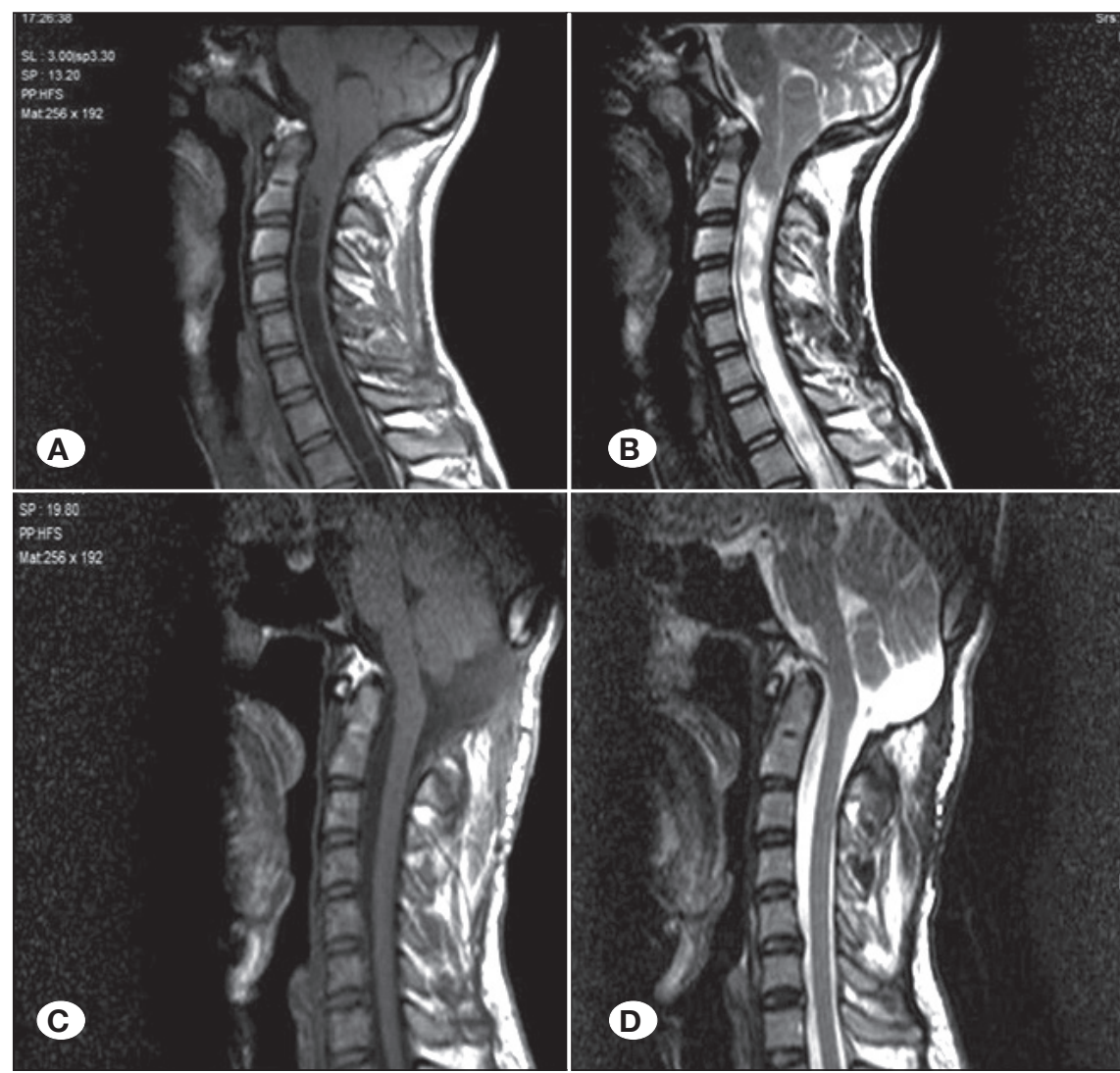

(D)

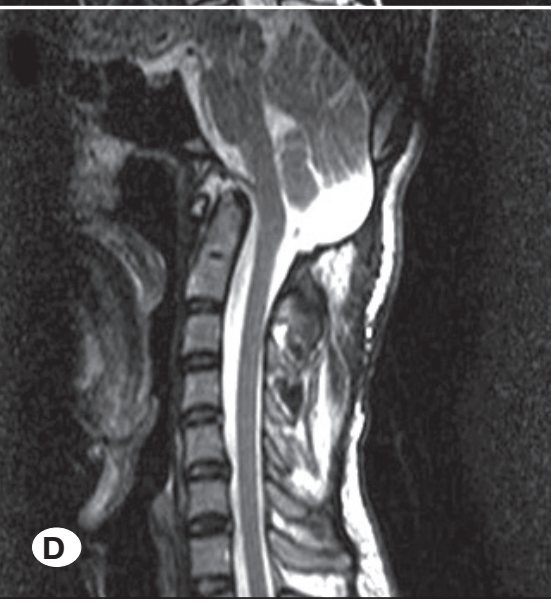

Figure 2: Preoperative sagittal T1 (A) and T2 (B) weighted magnetic resonance image demonstrates Chiari Type I malformation and syringomyelia in group 1. Postoperative sagittal T1 (C) and T2 (D) weighted images at 6 months after surgery shows a decrease in the size of the syrinx cavity.
Figure 3: Preoperative sagittal T1 (A) and T2 (B) weighted magnetic resonance image demonstrates Chiari Type I malformation and syringomyelia in group 2. Postoperative sagittal T1 (C) and T2 (D) weighted images at 6 months after surgery shows a decrease in the size of the syrinx cavity. 


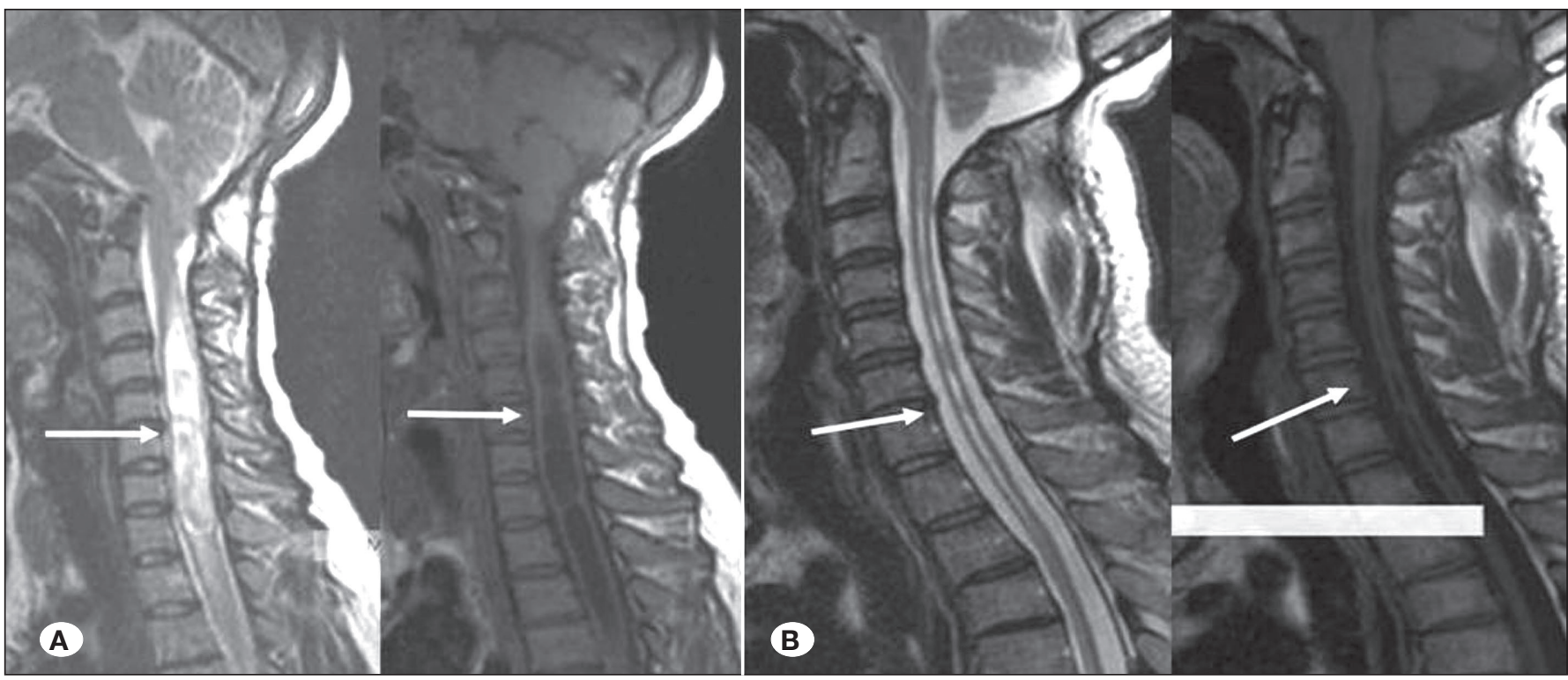

Figure 4: Postoperative image at 6 months after PFD and dural splitting surgery. The long multiseptated syrinx cavity continues to extend despite treatment (A). Postoperative image at 6 months after PFD and duraplasty surgery shows a decrease in the size of the syrinx cavity (B).
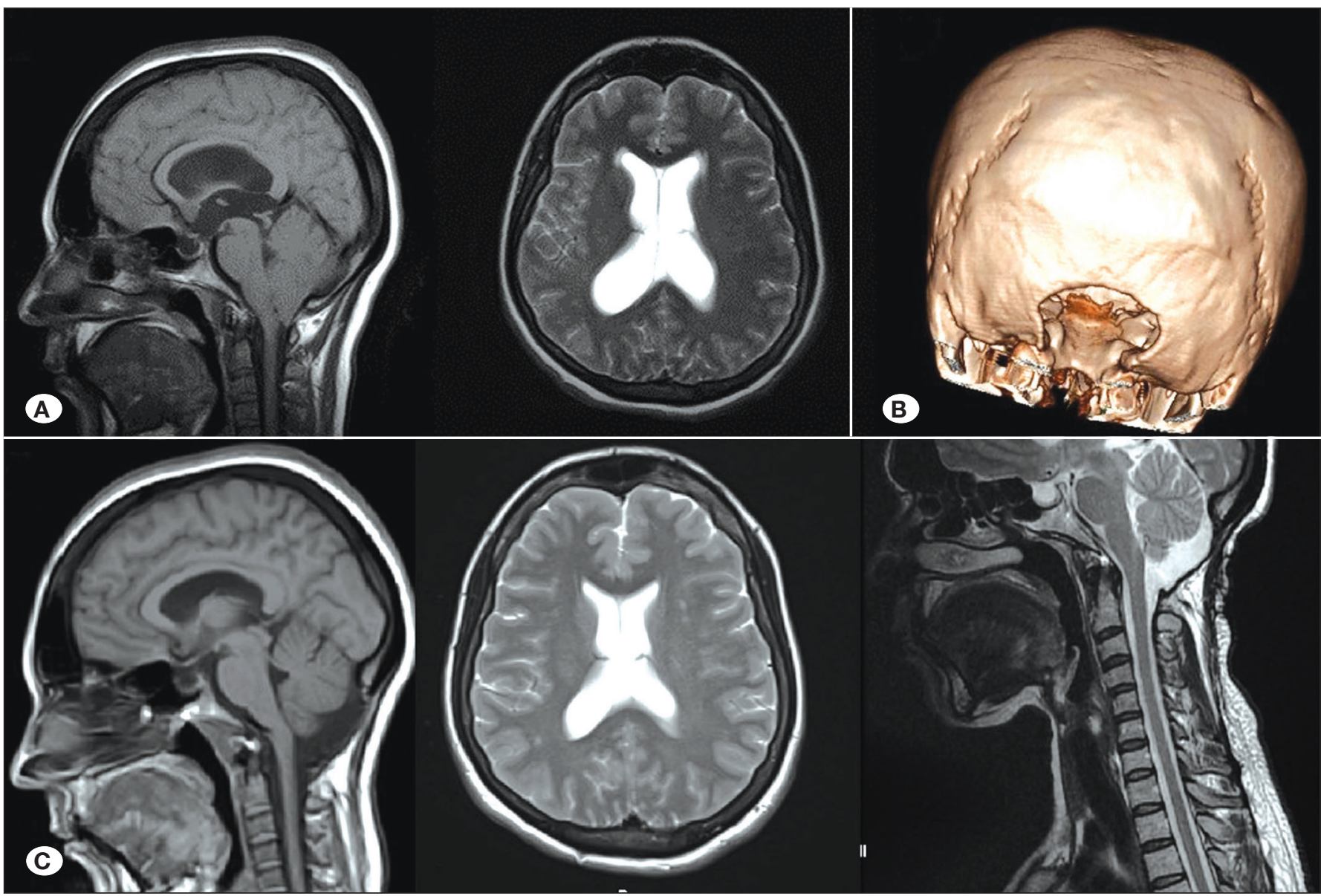

Figure 5: Preoperative sagittal T1 (A) and axial T2 (B) weighted images show Chiari Type I malformation and hydrocephalus (A). Postoperative images at 6 months after dural splitting surgery shows a regressed hydrocephalus (B and $\mathbf{C})$. 
Therefore, because of the operating time and complications with duraplasty, they suggested that dural splitting should be considered first in the treatment of patients with CMI (5). Munshi et al. reported regression in the syrinx cavity in 7 of 11 patients who underwent duraplasty and in 3 of 6 who underwent dural splitting (11). Similarly, Genitori et al. reported complete regression of the syrinx cavity in 8 of 10 patients with CMI (6). Litvack et al. performed duraplasty in 50 of 113 patients with larger syrinx cavities and dural splitting in 63 of 113 with smaller syrinx cavities. They found that the dural splitting technique was more beneficial in those with smaller cavities due to the cost of hospital care, length of hospital stay, and complications (9). In the present study, the syrinx cavity became smaller in group 2 than in group 1. We found that posterior fossa decompression (PFD) with dural splitting was not effective in treating syringomyelia, which has a long multiseptated syrinx cavity. Therefore, we recommend PFD with duraplasty as the most favorable method for treating patients with $\mathrm{CMI}$ with a long syrinx cavity.

Litvack et al. reported about 3 patients who were treated with antibiotics due to aseptic meningitis and 1 patient who underwent reoperation duraplasty for pseudomeningocele. Moreover, they performed duraplasty in 1 patient with progressive symptoms after dural splitting (9). Chauvet et al. reported a superficial wound infection at the incision in 1 patient who underwent dural splitting. Munshi et al. reported numerous complications, such as aseptic meningitis, wound infection, and CSF leakage, in the duraplasty group (4). In another study, there were similar complications, such as meningitis, CSF leakage, focal neurological deficit, and wound infection, in the duraplasty group. However, the authors reported inadequate decompression in 2 patients who underwent dural splitting (17). The complication rates in the present study are consistent with the data in the literature. Therefore, we found that PFD with dural splitting is better tolerated and is associated with fewer complications than PFD with duraplasty.

\section{CONCLUSION}

$\mathrm{CMI}$ continues to present a complex clinical picture to the clinician. The etiology of the malformation remains elusive and allows for various treatment approaches. To date, as per our knowledge, the relationship between TDD and syrinx cavity regression rate has not been reported. The present study is the first to show that there is no correlation between TDD and syrinx cavity regression rate. Demonstrating CSF flow on intraoperative USG is important in dural splitting surgery. The syrinx cavity is statistically more regressed in patients who undergo duraplasty; however, clinical outcomes are the same for the two groups. We are aware of the many complications with duraplasty. Therefore, dural splitting should be initially performed in patients with $\mathrm{CMI}$ with a small syrinx cavity or in patients without syringomyelia, and duraplasty can be performed if dural splitting fails to achieve regression of syrinx cavity or alleviate postoperative symptoms.

\section{ACKNOWLEDGEMENTS}

Preparation for publication of this article is partly supported by Turkish Neurosurgical Society.

\section{- REFERENCES}

1. Aliaga L, Hekman KE, Yassari R, Straus D, Luther G, Chen J, Sampat A, Frim D: A novel scoring system for assessing Chiari malformation type I treatment outcomes. Neurosurgery 70: 656-664; discussion 664-655, 2012

2. Cavender RK, Schmidt JH 3rd: Tonsillar ectopia and Chiari malformations: Monozygotic triplets. Case report. J Neurosurg 82: 497-500, 1995

3. Chang JS, Smiddy WE: Cost evaluation of surgical and pharmaceutical options in treatment for vitreomacular adhesions and macular holes. Ophthalmology 121:17201726, 2014

4. Chauvet D, Carpentier A, George B: Dura splitting decompression in Chiari type 1 malformation: Clinical experience and radiological findings. Neurosurg Rev 32:465470, 2009

5. Erdogan E, Cansever T, Secer HI, Temiz C, Sirin S, Kabatas S, Gonul E: The evaluation of surgical treatment options in the Chiari Malformation Type I. Turk Neurosurg 20: 303-313, 2010

6. Genitori L, Peretta P, Nurisso C, Macinante L, Mussa F: Chiari type I anomalies in children and adolescents: minimally invasive management in a series of 53 cases. Childs Nerv Syst 16: 707-718, 2000

7. Isu T, Sasaki H, Takamura H, Kobayashi N: Foramen magnum decompression with removal of the outer layer of the dura as treatment for syringomyelia occurring with Chiari I malformation. Neurosurgery 33:845-849; discussion 849-850, 1993

8. Klekamp J, Samii M: Introduction of a score system for the clinical evaluation of patients with spinal processes. Acta Neurochir (Wien) 123:221-223, 1993

9. Litvack ZN, Lindsay RA, Selden NR: Dura splitting decompression for Chiari I malformation in pediatric patients: Clinical outcomes, healthcare costs, and resource utilization. Neurosurgery 72:922-928; discussion 928-929, 2013

10. Milhorat TH, Chou MW, Trinidad EM, Kula RW, Mandell M, Wolpert C, Speer MC: Chiari I malformation redefined: Clinical and radiographic findings for 364 symptomatic patients. Neurosurgery 44:1005-1017, 1999

11. Munshi I, Frim D, Stine-Reyes R, Weir BK, Hekmatpanah J, Brown F: Effects of posterior fossa decompression with and without duraplasty on Chiari malformation-associated hydromyelia. Neurosurgery 46:1384-1389; discussion 13891390, 2000

12. Pillay PK, Awad IA, Little JR, Hahn JF: Symptomatic Chiari malformation in adults: A new classification based on magnetic resonance imaging with clinical and prognostic significance. Neurosurgery 28: 639-645, 1991 
13. Sahuquillo J, Rubio E, Poca MA, Rovira A, Rodriguez-Baeza A, Cervera C: Posterior fossa reconstruction: A surgical technique for the treatment of Chiari I malformation and Chiari l/syringomyelia complex-preliminary results and magnetic resonance imaging quantitative assessment of hindbrain migration. Neurosurgery 35:874-884; discussion 884-885, 1994

14. Selmi F, Davies KG, Weeks RD: Type I Chiari deformity presenting with profound sinus bradycardia: Case report and literature review. Br J Neurosurg 9: 543-545, 1995

15. Vaidya B, Sharma GR: Chiari malformations: Our experience. Nepal Journal of Neuroscience 9: 62-66, 2012
16. Yeh DD, Koch B, Crone KR: Intraoperative ultrasonography used to determine the extent of surgery necessary during posterior fossa decompression in children with Chiari malformation type I. J Neurosurg 105: 26-32, 2006

17. Yilmaz A, Kanat A, Musluman AM, Colak I, Terzi Y, Kayaci S, Aydin $Y$ : When is duraplasty required in the surgical treatment of Chiari malformation type I based on tonsillar descending grading scale? World Neurosurg 75:307-313, 2011 